\title{
An Empirical Test of Alternative Theories of Educational Inequality
}

\author{
Arthur Sakamoto, ${ }^{1}$ ChangHwan Kim, ${ }^{2}$ and Hyeyoung Woo ${ }^{3}$ \\ ${ }^{1}$ Department of Sociology, University of Texas, 1 University Station A1700, Austin, TX 78712-0118, USA \\ ${ }^{2}$ Department of Sociology, University of Kansas, Fraser Hall, Room 710, 1415 Jayhawk Boulevard, Lawrence, KS 66045-7556, USA \\ ${ }^{3}$ Department of Sociology, Portland State University, P.O. Box 751, Portland, OR 97207-0751, USA
}

Correspondence should be addressed to Hyeyoung Woo, hyeyoung@pdx.edu

Received 4 April 2012; Accepted 2 October 2012

Academic Editor: Alex W. H. Chan

Copyright (C) 2012 Arthur Sakamoto et al. This is an open access article distributed under the Creative Commons Attribution License, which permits unrestricted use, distribution, and reproduction in any medium, provided the original work is properly cited.

A classic issue in education centers on the nature of the relationship between schooling and labor market outcomes. Three general theories of this relationship are the human capital view, the market signal view, and the credentialist view. All three approaches predict a positive association between education and wages, but they differ in regard to its underlying causes. We argue that these theories may be fundamentally differentiated in terms of their implications for productivity, and we provide some relevant findings using productivity data for US manufacturing industries from 1976 to 1996 . The results most strongly support the market signal view which emphasizes the association between productivity and relative educational attainment due to the role of the latter in certifying more reliable and trainable workers.

\section{Introduction}

The positive correlation between schooling and labor force outcomes has been known for decades and has been observed in many studies using various units of analysis. More educated workers tend to have higher wages [1]. The prestige rankings of occupational titles are greater for workers with higher levels of schooling [2]. Regions, states, and metropolitan areas with more highly educated residents have higher average incomes [3]. Occupations and industries with more educated workers have higher earnings [4]. Educational expansion seems to be significantly associated with economic growth [5].

Although this association between schooling and income is widely observed in a variety of contexts, disagreement still exists regarding the causal nature of this association. We seek to contribute to this debate by providing empirical evidence that attempts to distinguish between different theoretical perspectives. Three basic models are considered: (1) the technical functional or human capital view (2) the market signal view and (3) the credentialist view.

\section{Theoretical Background}

2.1. The Technical Functional View. According to the technical functional view $[6,7]$, education directly augments economic productivity. Workers with more education are inclined to be more productive due to their schooling experiences. This view recognizes that while there are also other sources of worker productivity, education is very important in providing workers with the crucial components of the training and general skills required for competency in more complex jobs. As noted by Collins [6, page 1004] "...formal education provides the training, either in specific skills or in general capacities, necessary for more highly skilled jobs."

The technical functional view suggests that education improves an individual's productivity in several ways. First, education increases a person's cognitive skills, such as in mathematics and writing. Second, education normally provides training in work skills by increasing one's familiarity and facility with the technology involved in production, such as that with machines, materials, computers, or technical instruments. Third, education can increase an individual's 
productivity by conditioning important social skills, like the ability to communicate, to work with others, and to be reliable and disciplined.

According to Collins [6, page 1004], the technical functional view can be interpreted as being consistent with the general functional theory of social stratification. In brief, this functional theory states that education provides substantial components of the greater skills and training that are required for the competent performance of more complex jobs. In order to motivate people to endure the various costs incurred by completing additional schooling and undergoing more training, jobs that are more complex and in higher demand require greater rewards to the extent that an inadequate supply of competent and able persons would not otherwise be available.

An economic version of the technical functional view is human capital theory [7-9]. Additional theoretical elements in human capital theory are the assumptions that labor markets are highly competitive and that differences in workers' productivities reflect their varying stocks of human capital which are the driving forces underlying the wage distribution [10]. Common to both the technical functional view and human capital theory is the fundamental idea that education directly augments an individual's productive capacities. Education augments human capital.

This view provides a straightforward solution to the problems of poverty and inequality. Increases in the education of the poor and of the working class will correspondingly bring about increases in their incomes [11, pages 70-71], [10, page 69]. As discussed by Becker [8, page 86] and Thurow [12], a reduction in the inequality in the distribution of schooling should lessen the degree of inequality in the distribution of wages.

2.2. The Market Signal View. According to the market signal view, education certifies people in regard to their ability and trainability. Paradoxically, however, schooling does not substantially reinforce those traits in any direct way. The main value of education is to serve as a signal in a labor market where information about a person's abilities is highly imperfect [9]. Education is typically correlated with a worker's productive capacities and thus with her ultimate socioeconomic attainments, but education per se does not directly affect the economic output of an industry [12]. Stated alternatively, the role of education in the labor market is to enhance allocation [13].

A major assumption in the market signal view is that most work skills are learned on the job and in the workplace rather than in school. Students do not learn very much in school that actually enhances their economic performance. Actual work skills are said to be too far removed from the activities that come with schooling. Instead, work skills are developed through job experience and the on-the-job training that is informally provided by senior workers [10, 12]. Education is valued by employers because it serves as a valid signal of the extent to which an individual has discipline, trainability, and general capacity to absorb new knowledge.
As discussed by Thurow [12], those traits are valued by employers because of the salient role of on-the-job training in the development of work skills. An individual's education is a market signal that provides strong evidence to an employer that the worker can be readily trained to become a more productive worker. Education is thus associated with productivity but does not directly cause it. The association arises because people with more education tend to have more of those traits that make a person economically productivediscipline, trainability, and ability-but those traits are not significantly enhanced by schooling [9]. The association between education and economic productivity is said to be spurious due to a common cause (i.e., the individual's discipline, intelligence, trainability, and other productive traits).

The market signal view assumes that a worker's productive traits and capacities are often difficult to directly assess. This reinforces the reliance upon education as a certifying device. This may simply reflect the fact that information about workers' abilities, trainability, and potential productivity are just too difficult to accurately ascertain, measure, or observe. These problems of assessment or evaluation may especially be pronounced when the production process is highly interdependent and is characterized by nonconstant returns to scale, or when senior workers are crucial in providing training to junior workers [12].

Another typical assumption of the market signal view is that the labor market for better paying jobs consists of a set of slots that employers seek to fill with people who incur the lowest training costs-that is, people who learn quickly [12]. One important implication of this assumption is that a person's relative educational attainment is more important than her absolute educational attainment because relative educational attainment actually determines her place in the labor queue. In other words, although education is the primary screening device that employers value most in that it most accurately certifies who requires lower training costs "it is a person's relative position in the distribution of education that counts" [10, page 69].

In contrast to the technical functional view, the market signal view does not predict that the distribution of wages is affected much by changes in the distribution of education [10, page 69]. In regard to poverty, Levin [14, page 168] states that "in a way, we are describing a game of musical chairs [for good jobs]" because the fundamental problem of not having enough well-paying jobs is not substantially affected by the distribution of education. Changes in the distribution of education may affect who obtains the better jobs, but the poverty rate for the economy will not be significantly reduced because "there are still fewer chairs than there are people" [14, page 166]. In sum, the market signal view does not predict that increased schooling among the poor can significantly equalize the distribution of wages because education is only a certifying device that does not directly contribute to economic productivity.

2.3. The Credentialist View. The credentialist view is related to the market signal view in that both share the assumption that what students learn in school does not actually improve 
their economic performance in the workplace very much. While both approaches agree that education does not directly augment one's productivity (at least not significantly), the credentialist view goes one step further by claiming that education is not even correlated with productive abilities [6]. According to the credentialist view, the association between education and socioeconomic attainment is not due to any positive relationship with economic productivity.

To the contrary, the association is said to derive from class conflict and is related to discussions of cultural capital [6]. As discussed by Farkas [15], cultural capital signifies identity with a particular status culture that seeks to control access to the rewards and privileges of some group membership. Along with economic, social, and symbolic capital, cultural capital thus reflects the power of particular groups. According to Burris [16, page 465], "Employers rely on educational credentials in hiring and promoting not because of the technical skills these represent, but as a means of selecting people who are socialized into the dominant status culture." A "status culture" identifies an elite group with claims to moral superiority which does not, however, demarcate correspondingly higher economic productivity.

In general, the credentialist view maintains that education serves to promote exploitation in the labor market by reinforcing authoritative relations and by legitimating inequality in the distribution of wages [17]. Jobs which pay higher wages to college-educated workers do so not because those workers are actually more productive, but because their higher education has established them as being a member of a morally superior status group that deserves to not only be in power but also enjoy greater rewards $[6,18,19]$. Education thus serves the interests of the dominant social classes including their advantages in the intergenerational transmission of inequality. Education is a critical mechanism by which higher status groups can reinforce and pass on some of their higher status to their offspring [17].

\section{Productivity and Theories of Educational Stratification}

Given our research objectives, the most important difference among these models is that they differ with respect to the predictions they make about the relationship between schooling and productivity. According to the technical functional view, an increase in the quantity of schooling among workers should directly result in greater productivity because education is deemed to represent human capital. The credentialist view predicts that an increase in schooling does not increase productivity because the educational system only serves to perpetuate class inequality and exploitation. The intermediate position here is represented by the market signal view which predicts that industries which hire workers with higher relative educational attainment should have lower training costs which would indirectly increase productivity.

While one might argue that the individual is the most desirable unit of analysis [7, pages 583-584], objectively defined productivity statistics are not available for a broad representative sample of workers [20, pages 515-518]. Modern capitalism is characterized by an extensive division of labor and complex production processes. In contrast to the production systems of preindustrial societies in which an individual worker often produced much of the product that is sold or consumed, an individual worker in contemporary capitalism typically performs only a tiny subset of the total activities that are required in order to realize the sale of the product. The economic value resulting from the work activities of an individual worker is difficult to measure because her particular job activities alone usually do not yield a salable commodity.

In this context, we use a factors-of-production methodology to analyze the creation and measurement of economic value. This approach is appropriate because it recognizes the contributions of all of the various factors of production (i.e., capital, industry-specific technology, material supplies, and the labor of different types of employees including managers) that are involved in the realization of the sale of the product which is an important and direct indicator of its value. Our factors-of-production methodology uses data to empirically estimate the multivariate relationships between the value created and the quantities of the various inputs utilized in the production process.

In short, a more aggregate unit of analysis is appropriate for our investigation. From the standpoint of the technical functional view, workers who have more schooling should have developed more human capital. At the level of the industry, productivity is greater (ceteris paribus) if its workers have a higher average level of human capital. The argument that a measure of human capital at some aggregate level increases industrial productivity is well formulated in economics [5]. Indeed, this aggregate relationship may be the motivation underlying the invention of the term "human capital."

From the point of view of the market signal approach, employers value workers who are more highly educated because such workers tend to be more productive and to have lower training costs. Because schooling does not directly augment productivity, however, total years of schooling per seis not the most appropriate indicator of a person's level of certification. Rather, greater relative educational attainment is more important because schooling itself is said to be largely irrelevant to economic productivity. The value of the signal indicated by schooling derives from the person's relative standing in the ladder of educational competitiveness because her relative standing more accurately reveals her productive potential. The market signal view implies that productivity will be higher in industries where the workers have higher relative educational attainment.

In regard to the credentialist view, schooling is assumed to help sustain class inequality rather than economic efficiency or productivity. This approach assumes that schooling does not specifically relate to economic productivity and that an individual with less schooling is no less productive than an individual with more schooling. The implication of this view is that industrial productivity is not affected (ceteris paribus) by the educational attainment among the workers in a given industry. Greater variation in educational attainment among 
the employees of an industry may relate to its degree of social and economic inequality but not its productivity.

\section{Research Strategy and Methodology}

Our data consist of three-digit manufacturing industries for which there is an established tradition of economic statistics and data collection on productivity. We use an objectively defined measure of productivity, namely, the dollar value of the output produced (in millions of constant dollars) in a three-digit industry in a given year. Dollar value added is net of the costs of material and energy inputs, and preferably to actual quantities produced because net dollar value added takes into account both the quantity as well as the quality aspects of products.

In order to provide a more methodologically conservative test of our theoretical concerns, we restrict our study to manufacturing industries because productivity data are more likely to be valid and reliable for the manufacturing sector than for others, such as services where the output is less directly measured or quantifiable. Restricting the analysis of productivity to one sector also reduces the number of complications that might arise from the high degree of technological heterogeneity across sectors. Our analysis adopts an aggregate approach by using detailed industries as the unit of analysis because dollar value added is not defined at the level of the individual level (i.e., an individual working alone does not produce the entire product himself) and because data on productivity is not available at the individual level in any of the data sets that we use.

\section{Data}

Our key data source that provides annual information on productivity and other related factors for manufacturing industries is the Manufacturing Industry Database (NBERCES MID) which is compiled by the National Bureau of Economic Research and the Center for Economic Studies of the US Census Bureau [21]. These data are obtained from various official sources, most notably the Annual Survey of Manufactures and the Census of Manufactures. This database extends through 1996, and our analysis thus ends with that year.

However, this database does not provide any information on workers' characteristics in each manufacturing industry. We therefore use the NBER-CES MID in conjunction with other annual data from the Current Population Survey (CPS). We investigate the CPS beginning with 1979 because of its consistent use of occupational and industrial codes that are based on the 1970 Census Bureau classification. Workers' characteristics are summarized in terms of the proportions observed for various demographic and socioeconomic categories (i.e., gender, race, occupational category, educational level, etc.) in each detailed manufacturing industry for each year.

We matched the NBER-CES MID data on productivity (and other related factors) and the CPS data on workers' characteristics on the basis of three-digit Standard Industrial Classification (SIC) codes. That is, our unit of analysis is the three-digit SIC code. At this aggregate level, productivity (i.e., the dollar value of the total output of a manufacturing industry during a given year net of material and energy costs) and workers' characteristics (i.e., the proportions observed on various variables for the workers in a manufacturing industry during a given year) are linked for each three-digit SIC code in each year from 1979 to 1996.

\section{Variables and Statistical Model}

Our model is developed from the Cobb-Douglas production function which is well known and widely used in economics as well as sociology $[22,23]$. In our research context, the model is specified as

$$
V_{i t}=\alpha K_{i t}^{\beta k} L_{i t}^{\beta l} S_{i t}^{\beta s} R_{i t}^{\beta r} X_{i j t}^{\lambda j}
$$

where $V_{i t}$ refers to the total value added in the production process (i.e., the total dollar value of output minus material and energy costs in millions of constant 1996 dollars) by a given three-digit manufacturing industry $i$ in year $t ; K_{i t}$ refers to the total capital used in the production process (i.e., the total dollar rental cost in millions of constant 1996 dollars) by a given industry $i$ in year $t$; $L_{i t}$ refers to the total number of employees (i.e., in thousands of workers) by a given industry $i$ in year $t ; S_{i t}$ refers to the mean years of schooling completed by workers in a given industry $i$ in year $t ; R_{i t}$ refers to an indicator of mean relative educational attainment (i.e., a continuous variable with a theoretical range of 0 to 1 ) completed by workers in a given industry $i$ in year $t ; X_{i j t}$ refers to a set of control variables for a given industry $i$ in year $t$ including mean age, the percent female, the percent African-American, the percent Hispanic, the percent nonWhite Other, and the percent residing in metropolitan areas. $X_{i j t}$ also includes a linear term to indicate the year of data. This term increments by one annually (beginning in 1979) and indicates the effect of technological changes over time.

The indicator of relative educational attainment that we use (i.e., $R_{i t}$ ) is created by first breaking up each year of our data into 5-year age cohorts (16-20, 21-25, 26-30, 31-35, etc.). For each year, we next obtain the mean and the standard deviation of years of schooling completed for all employees (by age cohort) in the manufacturing sector. Using those two statistics (which vary by year and age cohort), the $Z$ score associated with the years of schooling for each individual employee is then computed. Each $Z$ score is then converted to its corresponding cumulative percentile based on the standard normal distribution (i.e., $\Phi)$. $R_{i t}$ refers to the mean of these cumulative percentiles for a given industry $i$ in year $t$.

This measure is motivated by the assumption that relative educational attainment is significant in that it refers to the ranking that an individual has in regard to productive capacity that is not generated by the distribution of schooling itself. Converting the $Z$ scores into their corresponding percentile based the standard normal distribution accomplishes this ranking without relying on the actual distribution of years of schooling itself. By breaking down the calculations by age and year, our measure further recognizes that the increase in 
average years of schooling completed over time implies that a given level of schooling for a more recent cohort would represent a lower relative ranking than would that level for an older cohort.

In order to estimate the parameters of (1), it may be transformed into a linear function by expressing it in terms of logarithms:

$$
\begin{aligned}
\ln V_{i t}= & \beta_{k} \ln K_{i t}+\beta_{l} \ln L_{i t}+\beta_{s} \ln S_{i t} \\
& +\beta_{r} \ln R_{i t}+\Sigma \lambda_{\mathrm{j}} \ln X_{i j t}+\alpha_{j}+\varepsilon_{i t},
\end{aligned}
$$

where $\varepsilon_{i t}$ refers to a random error term. In (2) the intercept term is expanded to vary for each industry. That is, the $\alpha_{j}$ represent fixed effects that allow for differences across industries in terms of technological factors or any other characteristics that are constant across the time period of our data.

Mean years of schooling (i.e., $\left.S_{i t}\right)$ and mean relative educational attainment (i.e., $R_{i t}$ ) are both included into (2) in order to evaluate theories of the role of education in the labor market. Two empirical results that would most strongly support the technical functional include (1) reject $\mathrm{H}_{0}: \beta_{s} \leq 0$; (2) fail to reject $\mathrm{H}_{0}: \beta_{r} \leq 0$. This set of findings would underscore the importance of the absolute amount of education (i.e., $S_{i t}$ ) obtained by workers in influencing productivity and would be consistent with the interpretation of schooling as representing stocks of human capital. Such results would also be contrary to the expectation of the market signal view which places greater emphasis on relative educational attainment (i.e., $R_{i t}$ rather than $S_{i t}$ ) as an indicator of one's productivity.

Thus, the opposite set of empirical findings would support the market signal view (i.e., fail to reject $\mathrm{H}_{0}$ : $\beta_{s} \leq$ 0 but reject $\left.\mathrm{H}_{0}: \beta_{r} \leq 0\right)$. In this case, mean number of years of schooling (net of relative educational attainment) has no positive effect on productivity. Interindustry variation in productivity over time is instead positively correlated with relative educational attainment. These empirical results that support the market signal view are exactly opposite to those that support the technical functional view. Nonetheless, the two contrasting views are not mutually exclusive. Both approaches would be supported to some degree if the empirical results reject both $\mathrm{H}_{0}: \beta_{s} \leq 0$ and $\mathrm{H}_{0}: \beta_{r} \leq 0$ simultaneously.

On the other hand, if the analysis fails to reject either $\mathrm{H}_{0}: \beta_{s} \leq 0$ or $\mathrm{H}_{0}: \beta_{r} \leq 0$ then schooling (in some form) affects productivity. For this reason, the credentialist view would be supported if the empirical results fail to reject both $\mathrm{H}_{0}$ : $\beta_{s} \leq 0$, and $\mathrm{H}_{0}$ : $\beta_{r} \leq 0$. This finding would be consistent with the credentialist view because productivity is not increased by schooling either in terms of years completed or relative educational attainment. In this case, education may be interpreted to be neither productive human capital nor an accurate market signal about a worker's productive capacities. Educational attainment simply has no positive net effect on economic productivity.

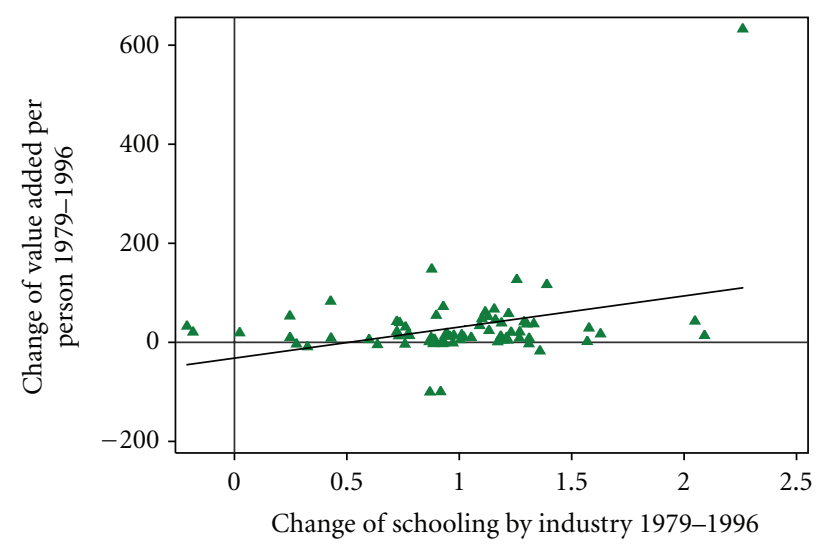

Figure 1: Change between 1979 and 1996 in productivity (value added per employee) and mean years of schooling across manufacturing industries.

\section{Empirical Results}

Descriptive statistics are shown in Table 1. Measured in terms of the total dollar value of output per employee, productivity increased from a mean of \$90.7 in 1979 to \$120.6 in 1996 (in thousands of constant 1996 dollars) across three-digit manufacturing industries. This change represents an increase of \$29.9 per worker (in thousands of constant 1996 dollars). On the other hand, mean employment (in thousands of workers) declined by 10.8 .

Table 1 also shows that workers in three-digit manufacturing industries became more highly educated over this period with only $15.1 \%$ being high school dropouts by 1996 . On average, employees also became slightly older, but no significant increase in the proportion female occurred in the manufacturing sector. The proportions that were White or African American declined slightly while the proportions that were Hispanic or other minority increased slightly.

For descriptive purposes, Figure 1 plots the change in productivity (i.e., the total value of output per employee in 1996 minus the total value of output per employee in 1976) versus the change in the schooling (i.e., the mean years of schooling in 1996 minus the mean years of schooling in 1976) across the three-digit manufacturing industries. In general, as indicated by the regression line indicated in Figure 1, a slight positive association is evident in the scatter plot.

Figure 2 plots the same change in productivity but with respect to the change in mean relative schooling (i.e., the mean of our measure of relative educational attainment in 1996 minus its mean in 1976) across the three-digit manufacturing industries. In general, the same slightly positive relationship is observed. This similarity is perhaps not surprising since the correlation between $S_{i t}$ and $R_{i t}$ is .93 (as shown in Table 5).

Although bivariate plots are suggestive, more multivariate analysis is needed due to the significant correlations between many of the various sources of productivity as shown in Table 5. Table 2 shows the estimates for several fixed regressions using the Cobb-Douglas model as described 
TABLe 1: Descriptive statistics by three-digit manufacturing industry, 1979-1996.

\begin{tabular}{|c|c|c|c|c|c|c|c|}
\hline \multirow{2}{*}{ Variables } & \multicolumn{4}{|c|}{ Total (1979 through 1996) } & \multirow{2}{*}{$\begin{array}{c}1979 \\
\text { Mean }\end{array}$} & \multirow{2}{*}{$\begin{array}{c}1996 \\
\text { Mean }\end{array}$} & \multirow{2}{*}{ Change } \\
\hline & Mean & Std. dev. & Min & Max & & & \\
\hline$\$$ Total value added ('millions) ${ }^{\mathrm{a}}$ & $4,617.5$ & $5,474.7$ & 256.0 & $46,766.5$ & $5,084.0$ & $4,822.7$ & -261.3 \\
\hline \$ Total real capital (' millions) ${ }^{\mathrm{a}}$ & $5,302.6$ & $9,877.2$ & 96.8 & $100,027.6$ & $7,371.3$ & $4,299.4$ & $-3,071.9$ \\
\hline$\$$ Value added $\left({ }^{\prime} 000\right)$ per worker ${ }^{\mathrm{a}}$ & 102.0 & 77.4 & 30.0 & 826.2 & 90.7 & 120.6 & 29.9 \\
\hline Employment ('000) & 46.9 & 54.67 & 4.6 & 443.4 & 54.3 & 43.4 & -10.8 \\
\hline Less than high school (\%) & 22.5 & 11.342 & 0.0 & 61.7 & 31.3 & 15.1 & -16.2 \\
\hline High school graduate (\%) & 42.9 & 6.681 & 0.0 & 100.0 & 40.3 & 42.1 & 1.8 \\
\hline Some college $(\%)$ & 20.2 & 6.038 & 0.0 & 41.3 & 17.8 & 24.5 & 6.7 \\
\hline $\mathrm{BA}(\%)$ & 11.0 & 6.380 & 0.0 & 50.0 & 7.9 & 13.6 & 5.7 \\
\hline Advanced degree $(\%)$ & 3.3 & 3.275 & 0.0 & 20.0 & 2.4 & 4.7 & 2.4 \\
\hline Mean age (in years) & 39.0 & 1.9 & 30.0 & 52.3 & 37.9 & 39.8 & 1.9 \\
\hline Female $(\%)$ & 33.1 & 16.5 & 0.0 & 86.4 & 32.8 & 32.3 & -.5 \\
\hline White (\%) & 80.4 & 8.1 & 20.0 & 100.0 & 82.1 & 78.3 & -3.8 \\
\hline African American (\%) & 9.9 & 5.2 & 0.0 & 40.0 & 10.1 & 9.2 & -.9 \\
\hline Hispanic (\%) & 7.0 & 4.8 & 0.0 & 60.0 & 5.8 & 9.1 & 3.4 \\
\hline Other racial/ethnic minority (\%) & 2.8 & 2.4 & 0.0 & 21.9 & 2.1 & 3.3 & 1.3 \\
\hline Metropolitan resident (\%) & 67.9 & 16.2 & 9.4 & 100.0 & 65.5 & 72.5 & 7.0 \\
\hline
\end{tabular}

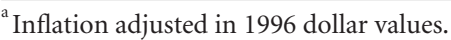

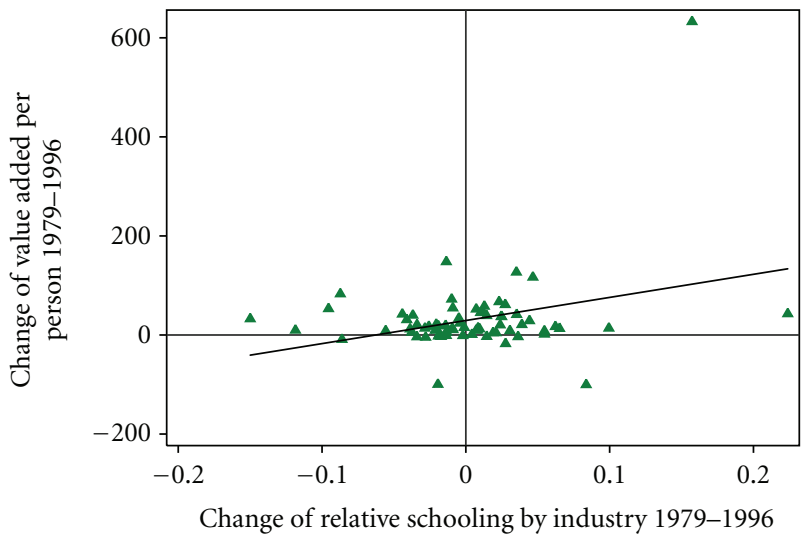

FIGURE 2: Change between 1979 and 1996 in productivity (value added per employee) and relative schooling across manufacturing industries.

above. In the most basic specification (i.e., model 1) the results confirm the significance of capital, labor employment, and the annual time trend in regard to productivity. In Model 2, mean years of schooling (i.e., $S_{i t}$ ) is added along with the control variables relating to the workforce. The net effect of $S_{i t}$ is highly positive and statistically significant. In the Cobb-Douglas model, the coefficients refer to elasticities so the estimated effect of .6583 indicates that, net of the other variables, a $1 \%$ increase in mean years of schooling results in a .6583\% increase in productivity. This is a large effect and is surpassed only by employment in model 2 .

The specification for model 3 is the same as model 2 except that mean relative educational attainment (i.e., $R_{i t}$ ) is included instead of mean years of schooling. The coefficient for mean relative educational attainment is statistically significant, and its estimate of .2315 indicates that, net of the other variables, a $1 \%$ increase in mean relative educational attainment results in a $.2315 \%$ increase in productivity. This elasticity for $R_{i t}$ is smaller than that for $S_{i t}$ in model 2.

In model 4 , both $R_{i t}$ and $S_{i t}$ are included. Model 4 corresponds to (2) above. The results show that, net of mean years of schooling and the other variables, the effect of mean relative educational attainment is increased to .4728 . Controlling for the other variables, a $1 \%$ increase in mean relative educational attainment results in a $.4728 \%$ increase in productivity. By contrast, the estimate of mean years of schooling is actually negative. It is also, however, not statistically significant at any conventional level.

In sum, the findings from model 4 lead to the conclusion to fail to reject $\mathrm{H}_{0}: \beta_{s} \leq 0$ and to reject $\mathrm{H}_{0}: \beta_{r} \leq 0$. In other words, mean years of schooling does not have a positive net effect on productivity whereas mean relative educational attainment does. These results support the market signal view but not the technical functional or credentialist views.

In order to assess the robustness of this conclusion we also estimated a different specification using the same variables contained in (2). Instead of using a Cobb-Douglas model, we used the same dependent variable and covariates in a translog (or "transcendental logarithmic") production function [24]. This specification is more flexible because it allows for the possibility of more nonlinearities and interactions between the covariates. The results for this regression specification are shown in Table 4.

Due to the nonlinearities and interactions, interpreting the net effect of any particular covariate is more complicated when using a translog production function. We have therefore computed these net effects (evaluated at the means of covariates) as shown in Table 3 . The calculated elasticity for mean relative educational attainment for the full specification (i.e., model 3) in Table 3 indicates that, net 
TABLE 2: Estimates of fixed effects models of productivity using Cobb-Douglas function.

\begin{tabular}{|c|c|c|c|c|}
\hline & & Fixec & nodels & \\
\hline & Model 1 & Model 2 & Model 3 & Model 4 \\
\hline Real capital & $0.1781^{* * *}(0.0269)$ & $0.1701^{* * *}(0.0268)$ & $0.1652^{* * *}(0.0268)$ & $0.1612^{* * *}(0.0269)$ \\
\hline Employment & $0.8959 * * *(0.0231)$ & $0.9095^{* * *}(0.0233)$ & $0.9077^{* * *}(0.0231)$ & $0.9027^{* * *}(0.0233)$ \\
\hline Year & $0.0134^{* * *}(0.0007)$ & $0.0100^{* * *}(0.0010)$ & $0.0131^{* * *}(0.0008)$ & $0.0169^{* * *}(0.0026)$ \\
\hline Years of schooling & & $0.6583^{* * *}(0.1697)$ & & $-0.8463(0.5562)$ \\
\hline Relative schooling & & & $0.2315^{* * *}(0.0507)$ & $0.4728^{* *}(0.1665)$ \\
\hline Experience & & $0.0060(0.0566)$ & $-0.0382(0.0533)$ & $-0.1033(0.0683)$ \\
\hline Female (\%) & & $0.0034(0.0053)$ & $0.0032(0.0053)$ & $0.0023(0.0053)$ \\
\hline Black (\%) & & $-0.0001(0.0016)$ & $-0.0001(0.0016)$ & $-0.0001(0.0016)$ \\
\hline Hispanic (\%) & & $0.0006(0.0012)$ & $0.0007(0.0012)$ & $0.0006(0.0012)$ \\
\hline Other race (\%) & & $-0.0001(0.0008)$ & $-0.0002(0.0008)$ & $-0.0002(0.0008)$ \\
\hline Metro (\%) & & $0.0758^{* *}(0.0282)$ & $0.0705 *(0.0282)$ & $0.0680 *(0.0282)$ \\
\hline Constant & $3.3039 * * *(0.1996)$ & $1.7077 * *(0.5518)$ & $3.7017^{* * *}(0.2583)$ & $6.2405^{* * *}(1.6882)$ \\
\hline$R$-squared & .988 & .989 & .989 & .989 \\
\hline Sigma $u$ & .4023 & .3735 & .3733 & .3777 \\
\hline Sigma $e$ & .1034 & .1025 & .1022 & .1022 \\
\hline $\mathrm{Bic}$ & -2193.908 & -2174.008 & -2180.135 & -2175.471 \\
\hline$N$ & 1262 & 1262 & 1262 & 1262 \\
\hline
\end{tabular}

The year variable is linear and increments by one annually beginning in 1979 .

${ }^{*} P<0.05,{ }^{* *} P<0.01,{ }^{* * *} P<0.001$ (two tailed tests).

TABLE 3: Estimated elasticities for covariates using translog production variable of productivity.

\begin{tabular}{lccc}
\hline Variable & Translog model 1 & $\begin{array}{c}\text { Fixed effects models } \\
\text { Translog model 2 }\end{array}$ & Translog model 3 \\
\hline Real capital & .2220 & .1862 & .1211 \\
Employment & .8872 & .8969 & .8901 \\
Years of schooling & & .1299 & -.6369 \\
Relative schooling & .1728 & .4165 \\
Experience & & -.1403 \\
Female (\%) & & .0261 \\
Black (\%) & & .0113 \\
Hispanic (\%) & & -.0085 \\
Other minority (\%) & & .0010 \\
Metro (\%) & & .1065 \\
\hline
\end{tabular}

Elasticity for a variable $v$ is calculated as elasticity ${ }_{v}=\beta_{v}+\left(\delta_{v} \times \bar{X}_{v}\right)+\sum\left(\gamma_{v w} \times \bar{X}_{w}\right)$.

of mean years of schooling and the other variables, a $1 \%$ increase in $R_{i t}$ results in a $.4165 \%$ increase in productivity. This estimate is fairly close to that reported in Table 2 based on Cobb-Douglas model.

The results for model 3 in Table 3 also show that the elasticity for $S_{i t}$ is negative. That is, net of mean relative educational attainment, mean years of schooling does not have a positive effect on productivity. Thus, model 3 in Table 3 yields the same substantive conclusion as model 4 in Table 2 which is that relative educational attainment increases productivity whereas mean years of schooling does not. Both the translog production function and the CobbDouglas model thus lead to the rejection of the technical functional and credentialist views in favor of the market signal view.

\section{Discussion}

Our primary research concern has been to empirically evaluate theories of educational stratification. They have important implications for understanding how economic inequality is generated in the labor market. Organizing prior literature into three major approaches, our empirical results most strongly support the market signal view. In the full multivariate analysis given by (2) using the Cobb-Douglas model, the net effect of mean relative educational attainment on productivity is positive and statistically significant while the net effect of mean years of schooling is negative and not statistically significant (as shown in Model 4 in Table 2). These results indicate that, as predicted by the market signal view, manufacturing productivity seems to be more 
TABLE 4: Fixed effects model estimates of education on industrial productivity using translog production function.

\begin{tabular}{|c|c|c|c|}
\hline & TL model 1 & TL model 2 & TL model 3 \\
\hline Real capital & $0.2230(0.2515)$ & $0.1436(0.2304)$ & $0.2242(0.2371)$ \\
\hline Employment & $0.6418^{* * *}(0.1207)$ & $0.8600 * * *(0.1121)$ & $0.7982 * * *(0.1249)$ \\
\hline Capital squared & $0.1355^{* * *}(0.0365)$ & $0.0999 * *(0.0341)$ & $0.0696^{*}(0.0355)$ \\
\hline Labor squared & $0.5543^{* * *}(0.0466)$ & $0.4647^{* * *}(0.0422)$ & $0.4285^{* * *}(0.0444)$ \\
\hline Emp $*$ capital & $-0.2399 * * *(0.0262)$ & $-0.2033^{* * *}(0.0242)$ & $-0.1782 * * *(0.0259)$ \\
\hline Year & $0.0124^{* * *}(0.0007)$ & $0.0129 * * *(0.0026)$ & $0.0155^{* * *}(0.0031)$ \\
\hline Years of schooling & & $-87.0753^{* * *}(20.7014)$ & $-102.6303^{* *}(31.3719)$ \\
\hline Relative schooling & & $24.5696^{* * *}(6.7510)$ & $21.4015^{*}(9.9690)$ \\
\hline Schooling squared & & $32.6942 * * *(7.5034)$ & $37.8036^{* * *}(9.7734)$ \\
\hline Rel. sch. squared & & $2.0907 *(0.8484)$ & $1.3188(1.0452)$ \\
\hline Schooling $*$ rel. sch. & & $-9.3522 * * *(2.4396)$ & $-7.9795 *(3.0930)$ \\
\hline Experience & & & $3.1850(7.7602)$ \\
\hline Female (\%) & & & $-2.4514 *(1.0426)$ \\
\hline Black (\%) & & & $-1.3270 * * *(0.2446)$ \\
\hline Hispanic (\%) & & & $0.1179(0.1270)$ \\
\hline Other race $(\%)$ & & & $-0.0178(0.0881)$ \\
\hline Metro (\%) & & & $1.0503(1.9101)$ \\
\hline Experience squared & & & $-2.4411^{* *}(0.9318)$ \\
\hline Female squared (\%) & & & $0.0039(0.0085)$ \\
\hline Black squared (\%) & & & $0.0021(0.0011)$ \\
\hline Hispanic squared (\%) & & & $-0.0010(0.0009)$ \\
\hline Other race squared (\%) & & & $0.0002(0.0008)$ \\
\hline Metro squared (\%) & & & $0.1666 *(0.0806)$ \\
\hline Experience $*$ schooling & & & $1.7921(2.2292)$ \\
\hline Female $*$ schooling $(\%)$ & & & $0.8065^{* *}(0.2969)$ \\
\hline Black $*$ schooling $(\%)$ & & & $0.4274^{* * *}(0.0778)$ \\
\hline Hispanic $*$ schooling $(\%)$ & & & $-0.0248(0.0399)$ \\
\hline Other race $*$ schooling $(\%)$ & & & $-0.0064(0.0269)$ \\
\hline Metro $*$ schooling $(\%)$ & & & $-0.4207(0.5372)$ \\
\hline Experience $*$ rel. sch. & & & $-0.4121(0.7493)$ \\
\hline Female $*$ rel. sch. $(\%)$ & & & $-0.2076(0.1066)$ \\
\hline Black $*$ rel. sch. $(\%)$ & & & $-0.1014^{* * *}(0.0239)$ \\
\hline Hispanic $*$ rel. sch. $(\%)$ & & & $0.0226(0.0125)$ \\
\hline Other race $*$ rel. sch. $(\%)$ & & & $-0.0128(0.0094)$ \\
\hline Metro $*$ rel. sch. $(\%)$ & & & $0.2298(0.2035)$ \\
\hline Female $*$ experience $(\%)$ & & & $0.0949(0.1196)$ \\
\hline Black $*$ experience $(\%)$ & & & $0.0547^{* * *}(0.0139)$ \\
\hline Hispanic $*$ experience $(\%)$ & & & $-0.0125(0.0111)$ \\
\hline Other race $*$ experience $(\%)$ & & & $0.0103(0.0078)$ \\
\hline Metro $*$ experience $(\%)$ & & & $0.1212(0.2425)$ \\
\hline Black $* \%$ female $(\%)$ & & & $-0.0066^{*}(0.0033)$ \\
\hline Hispanic $* \%$ female $(\%)$ & & & $0.0075^{* *}(0.0025)$ \\
\hline Other race $* \%$ female $(\%)$ & & & $0.0017(0.0014)$ \\
\hline Metro $* \%$ female $(\%)$ & & & $-0.0165(0.0341)$ \\
\hline Hisp $* \%$ Black $(\%)$ & & & $-0.0000(0.0002)$ \\
\hline Other $* \%$ Black $(\%)$ & & & $-0.0006^{* *}(0.0002)$ \\
\hline Metro $* \%$ Black $(\%)$ & & & $-0.0034(0.0070)$ \\
\hline Other $* \%$ Hisp. $(\%)$ & & & $0.0002(0.0002)$ \\
\hline Metro $* \%$ Hisp. $(\%)$ & & & $-0.0075^{*}(0.0035)$ \\
\hline Metro $* \%$ other $(\%)$ & & & $0.0110^{* * *}(0.0031)$ \\
\hline Constant & $2.8603 * *(0.9488)$ & $119.1650 * * *(28.4682)$ & $129.6294 *(51.3672)$ \\
\hline
\end{tabular}


TABle 4: Continued.

\begin{tabular}{lccc}
\hline & TL model 1 & TL model 2 & TL model 3 \\
\hline$R$ squared & .5433796 & .6372571 & .6652987 \\
Sigma $u$ & .3304505 & .3541423 & .3691016 \\
Sigma $e$ & .1105096 & .0984968 & .0946131 \\
Bic & -2014.7 & -2274.794 & -2140.266 \\
$N$ & 1262 & 1262 & 1262 \\
\hline
\end{tabular}

${ }^{*} P<0.05,{ }^{* *} P<0.01,{ }^{* * *} P<0.001$.

TABle 5: Correlation matrix.

\begin{tabular}{|c|c|c|c|c|c|c|c|c|c|c|c|}
\hline & VAD & Capital & Emp. & Sch. & Rel. sch. & Exp. & Female & Black & Hisp. & Other & Metro \\
\hline VAD & 1.0000 & & & & & & & & & & \\
\hline Capital & $\begin{array}{c}0.7195 \\
(0.0000)\end{array}$ & 1.0000 & & & & & & & & & \\
\hline Employment & $\begin{array}{c}0.7678 \\
(0.0000)\end{array}$ & $\begin{array}{c}0.3833 \\
(0.0000)\end{array}$ & 1.0000 & & & & & & & & \\
\hline Schooling & $\begin{array}{c}0.5010 \\
(0.0000)\end{array}$ & $\begin{array}{c}0.2884 \\
(0.0000)\end{array}$ & $\begin{array}{c}0.2156 \\
(0.0000)\end{array}$ & 1.0000 & & & & & & & \\
\hline Relative sch. & $\begin{array}{c}0.4791 \\
(0.0000)\end{array}$ & $\begin{array}{c}0.3071 \\
(0.0000)\end{array}$ & $\begin{array}{c}0.2641 \\
(0.0000)\end{array}$ & $\begin{array}{c}0.9328 \\
(0.0000)\end{array}$ & 1.0000 & & & & & & \\
\hline Experience & $\begin{array}{l}-0.2361 \\
(0.0000)\end{array}$ & $\begin{array}{l}-0.0743 \\
(0.0083)\end{array}$ & $\begin{array}{l}-0.1262 \\
(0.0000)\end{array}$ & $\begin{array}{l}-0.5811 \\
(0.0000)\end{array}$ & $\begin{array}{l}-0.4767 \\
(0.0000)\end{array}$ & 1.0000 & & & & & \\
\hline Female & $\begin{array}{c}-0.0876 \\
(0.0018)\end{array}$ & $\begin{array}{l}-0.2247 \\
(0.0000)\end{array}$ & $\begin{array}{c}-0.0268 \\
(0.3411)\end{array}$ & $\begin{array}{c}-0.1168 \\
(0.0000)\end{array}$ & $\begin{array}{c}-0.1433 \\
(0.0000)\end{array}$ & $\begin{array}{c}0.0931 \\
(0.0006)\end{array}$ & 1.0000 & & & & \\
\hline Black & $\begin{array}{l}-0.0722 \\
(0.0103)\end{array}$ & $\begin{array}{c}-0.0587 \\
(0.0369)\end{array}$ & $\begin{array}{l}-0.0600 \\
(0.0331)\end{array}$ & $\begin{array}{c}-0.3384 \\
(0.0000)\end{array}$ & $\begin{array}{l}-0.3655 \\
(0.0000)\end{array}$ & $\begin{array}{c}0.2054 \\
(0.0000)\end{array}$ & $\begin{array}{c}0.1103 \\
(0.0001)\end{array}$ & 1.0000 & & & \\
\hline Hispanic & $\begin{array}{l}-0.1725 \\
(0.0000)\end{array}$ & $\begin{array}{l}-0.1635 \\
(0.0000)\end{array}$ & $\begin{array}{l}-0.1581 \\
(0.0000)\end{array}$ & $\begin{array}{c}-0.2056 \\
(0.0000)\end{array}$ & $\begin{array}{c}-0.2888 \\
(0.0000)\end{array}$ & $\begin{array}{c}0.0065 \\
(0.8122)\end{array}$ & $\begin{array}{c}0.4144 \\
(0.0000)\end{array}$ & $\begin{array}{l}-0.0050 \\
(0.8539)\end{array}$ & 1.0000 & & \\
\hline Other & $\begin{array}{c}0.0669 \\
(0.0175)\end{array}$ & $\begin{array}{c}-0.0183 \\
(0.5157)\end{array}$ & $\begin{array}{c}0.0219 \\
(0.4372)\end{array}$ & $\begin{array}{c}0.2091 \\
(0.0000)\end{array}$ & $\begin{array}{c}0.1397 \\
(0.0000)\end{array}$ & $\begin{array}{c}-0.2551 \\
(0.0000)\end{array}$ & $\begin{array}{c}0.3025 \\
(0.0000)\end{array}$ & $\begin{array}{l}-0.0401 \\
(0.1414)\end{array}$ & $\begin{array}{c}0.2999 \\
(0.0000)\end{array}$ & 1.0000 & \\
\hline Metro & $\begin{array}{c}0.2820 \\
(0.0000)\end{array}$ & $\begin{array}{c}0.1058 \\
(0.0002)\end{array}$ & $\begin{array}{c}0.1116 \\
(0.0001)\end{array}$ & $\begin{array}{c}0.6152 \\
(0.0000)\end{array}$ & $\begin{array}{c}0.6279 \\
(0.0000)\end{array}$ & $\begin{array}{l}-0.2588 \\
(0.0000)\end{array}$ & $\begin{array}{c}0.0600 \\
(0.0279)\end{array}$ & $\begin{array}{l}-0.2736 \\
(0.0000)\end{array}$ & $\begin{array}{c}0.0999 \\
(0.0002)\end{array}$ & $\begin{array}{c}0.2303 \\
(0.0000)\end{array}$ & 1.0000 \\
\hline
\end{tabular}

Numbers within parenthesis are $P$ values.

dependent on the relative ranking of the schooling than on the actual quantity or years of schooling completed.

Our findings do not support the credentialist view. In Models 2 through 4 in Table 2, some measure of schooling (i.e., either years of schooling or relative educational attainment) has a positive and substantial net effect on productivity. While some aspects of status reproduction and cultural capital may certainly be implicated in certain sectors of the educational system, our results do not support the general contention that hiring more educated workers has no systematic impact of productivity, at least not in the US manufacturing sector.

The technical functional view is also not supported by our findings. The multivariate analysis reveals that the actual quantity of schooling (i.e., years of schooling) does not have a positive effect on productivity after taking into account the relative ranking of schooling. As discussed earlier, conventional economics portrays schooling as stocks of human capital that are directly engaged in augmenting the effectiveness of production processes. Although this imagery has been powerful and influential in the social sciences, the human capital prediction is not borne out in our results.
For the period of data that we investigate, a fairly high level of basic educational achievement was already characteristic of the majority of workers in the U.S. manufacturing sector. As shown in Table 1 and as was noted earlier, by 1996 only $15.1 \%$ of workers in this sector did not have a high school degree. By that time, $42.1 \%$ were high school graduates, $24.5 \%$ had some college, $13.6 \%$ had bachelor's degrees and $4.7 \%$ actually had advanced degrees (as shown in Table 1). Given that about two-thirds of employment in this sector during this time period consists of blue-collar occupations [25] such as manual workers, machine operatives, assembly line workers, and craftsmen, the majority of important work skills were likely learned on the job itself (given that the workers already had basic quantitative and literary competencies). Our results may thus be interpreted to indicate that marginal improvements in additional years of academic achievement do not appear to have any net positive effect on productivity after taking into account the relative educational achievement of the workforce in this sector over this time period.

Because of the heavy concentration of blue-collar occupations in manufacturing industries (especially during the 
20th century before much of the rise of sophisticated robotics and computerized technology in manufacturing production), traditional academic skills associated with a college education may have been less relevant to adequate job performance and ultimately productivity in this sector. Nonetheless, for exploratory purposes, we estimated additional models (which are available upon request from the authors) which utilize an alternative measure of market signaling, namely, the log of the proportion of workers with a high school degree, the log of the proportion of workers with some college, and the log of the proportion of workers with at least a bachelor's degree. In this specification, the coefficient for relative schooling was again highly statistically significant and substantively large while the other variables were not (except for the log of the proportion of workers with a high school degree which was statistically significant at the .05 level, but the estimate was actually negative contrary to the prediction of the technical functional view). These results as well as those from a few other exploratory regressions generally confirm that relative schooling as we have measured it has a positive net effect on productivity in contrast to indicators of highest completed educational levels.

As shown in Table 5 and as was duly noted above, the correlation between mean years of schooling and mean relative educational attainment is quite high (i.e., .93) in our data set. Such a high correlation is not surprising given the nature of aggregated data (which lacks person-level variation across individual workers) and the close conceptual linkage between years of schooling completed and relative educational attainment. Despite this high correlation, however, we reiterat the major results for the full specification (i.e., Model 4 in Table 2) which indicates that the net effect of relative educational attainment is statistically significant while the net effect of years of schooling is not. That is, our results are not ambiguous due to classical multicollinearity in which two variables are each statistically insignificant using a $t$-test but jointly statistically significant using an $F$-test [26].

Nonetheless, the high correlation between relative educational attainment and years of schooling does raise the issue of how robust the estimates are (i.e., whether the coefficients and substantive conclusions might change if the model specifications were changed slightly). To address this concern, our results shown in Table 3 using the translog specification are quite relevant. As mentioned earlier, this model is a somewhat different functional form from the standard Cobb-Douglas function. The fact that our basic substantive conclusions are the same in Table 3 using the translog model reinforces the robustness of our prior estimates in Table 2.

Furthermore, we estimated two additional models in which we used residualized measures of mean years of school and mean relative educational attainment. These residualized measures refer to the respective variable after it has been statistically "purged" of its association with the other. The residualized measure of mean years of schooling refers to the residual from an OLS simple regression of that variable using mean relative educational attainment as the independent variable while the residualized measure of mean relative educational attainment refers to the residual from an OLS simple regression of that variable using mean years of schooling as the independent variable. By construction, each of these residualized variables is necessarily uncorrelated with the other indicator of education.

In separate Cobb-Douglas models, we used the residualized measures rather than the original measure of education. The results (which are available upon request from the authors) confirm the robustness of our earlier estimates. In the regression in which the residualized measure of mean relative educational attainment is used (which is uncorrelated with mean years of schooling) the coefficient is large and statistically significant. In the regression in which the residualized measure of mean years of schooling is used (which is uncorrelated with mean relative educational attainment) the coefficient has the wrong sign (i.e., it is negative) and is not statistically significant. These findings support our conclusion that improved relative educational attainment enhances productivity in these industries whereas more years of schooling does not.

\section{Conclusions}

No study by itself, however, can ever be fully conclusive. Additional research is needed using other model specifications and other measures of productivity in order to further assess the robustness of our results. Our findings are limited to the manufacturing sector which employs only a small portion of the total workforce. As other industrial sectors begin to develop more reliable measures of productivity (e.g., education, health, utilities, and public administration) then future studies may replicate our approach as such data become adequately available.

Building upon our approach, more sophisticated models might also be developed to incorporate occupational variables. For some occupational groups, high levels of educational achievement may be rewarded more as an important a market signal (e.g., managers) than perhaps for other occupations (e.g., sales workers). There may be also some specific occupations where appropriate training in the field enhances more relevant human capital skills (e.g., electrical engineers). If suitable data could be obtained, then more complex models may be investigated that build upon our approach to incorporate variables pertaining to occupation and field of study among persons with a college degree. Although difficult to obtain, college quality or institutional prestige may be another dimension of educational attainment that may possibly be becoming more important in recent years.

Additional research may also investigate more about technological change. Our regression model includes fixed effects for each industry as well as an annual increment that is represented by a control variable to indicate the year. One could elaborate upon our approach to investigate whether technological change may have been more pronounced for some industries rather than others. Such an analysis might be more feasible (i.e., have more degrees of freedom) with data spanning a greater time period or with more direct measures of technological change. We hope that future research will 
build upon our efforts here to develop more advanced analyses.

\section{References}

[1] D. Card, "The causal effect of education on earnings," in Handbook of Labor Economics, O. Ashenfelter and D. Card, Eds., vol. 3, pp. 1801-1863, North-Holland, Amsterdam, The Netherlands, 1999.

[2] O. D. Duncan, "A socioeconomic index for all occupations," in Occupations and Social Status, A. J. Reiss Jr., Ed., pp. 109-138, Free Press, New York, NY, USA, 1961.

[3] B. R. Chiswick, Income Inequality: Regional Analyses within Human Capital Model, National Bureau of Economic Research, New York, NY, USA, 1974.

[4] W. T. Dickens and L. F. Katz, "Inter-industry wage differences and industry characteristics," in Unemployment and the Structure of Labor Markets, K. Lang and J. S. Leonard, Eds., pp. 4889, Basil Blackwell, New York, NY, USA, 1987.

[5] D. W. Jorgenson and B. M. Fraumeni, "Investment in education and U.S. economic growth," in Productivity, vol. 1 of Postwar U.S. Economic Growth, pp. 371-388, MIT Press, Cambridge, Mass, USA, 1995.

[6] R. Collins, "Functional and conflict theories of educational stratification," American Sociological Review, vol. 36, pp. 10021019, 1971.

[7] R. Rubinson and I. Browne, "Education and the economy," in Handbook of Economic Sociology, N. J. Smelser and R. Swedberg, Eds., pp. 581-599, Princeton University Press, Princeton, NJ, USA, 1994.

[8] G. S. Becker, Human Capital, University of Chicago Press, Chicago, Ill, USA, 2nd edition, 1975.

[9] A. Weiss, "Human capital versus signalling explanations of wages," Journal of Economic Perspectives, vol. 9, pp. 133-154, 1995.

[10] A. B. Sørensen and L. Arne Kalleberg, "An outline of a theory of the matching of persons to jobs," in Sociological Perspectives on Labor Markets, I. Berg, Ed., pp. 49-474, New York, NY, USA, 1981.

[11] H. J. Aaron, Politics and the Professors, Brookings Institution, Washington, DC, USA, 1978.

[12] L. C. Thurow, Generating Inequality: Mechanisms of Distribution in the U.S. Economy, Basic Books, New York, NY, USA, 1975.

[13] A. C. Kerckhoff, "The status attainment process: socialization or allocation?” Social Forces, vol. 55, pp. 368-381, 1976.

[14] H. M. Levin, "A decade of policy developments in improving education and training for low-income populations," in $A$ Decade of Federal Antipoverty Programs, R. H. Haveman, Ed., pp. 123-188, Academic Press, New York, NY, USA, 1977.

[15] G. Farkas, Human Capital or Cultural Capital? Ethnicity and Poverty Groups in an Urban School District, Aldine De Gruyter, New York, NY, USA, 1996.

[16] V. Burris, "The social and political consequences of overeducation," American Sociological Review, vol. 48, pp. 454-467, 1983.

[17] S. Bowles and H. Gintis, Schooling in Capitalist America, Basic Books, New York, NY, USA, 1976.

[18] I. Berg, Education and Jobs: The Great Training Robbery, Beacon Press, Boston, Mass, USA, 1970.

[19] P. Bourdieu, "Cultural reproduction and social reproduction," in Power and Ideology in Education, J. Karabel and A. H. Halsey, Eds., pp. 487-511, Oxford University Press, New York, NY, USA, 1977.
[20] A. B. Sørensen, "Firms, wages, and incentives," in Handbook of Economic Sociology, N. J. Smelser and R. Swedberg, Eds., pp. 504-528, Princeton University Press, Princeton, NJ, USA, 1994.

[21] E. J. Bartelsman and W. Gray, "The NBER manufacturing productivity database," Technical Working Paper 205, National Bureau of Economic Research, Cambridge, Mass, USA, 1996.

[22] P. B. Walters and R. Rubinson, "Educational expansion and economic output in the United States, 1890-1969: a production function analysis," American Sociological Review, vol. 48, no. 4, pp. 480-493, 1983.

[23] R. M. Stolzenberg and K. C. Land, "Causal modeling and survey research," in Handbook of Survey Research, P. H. Rossi, J. D. Wright, and A. B. Anderson, Eds., pp. 613-675, Academic Press, New York, NY, USA, 1983.

[24] L. R. Christensen, D. W. Jorgenson, and L. J. Lau, "Transcendental logarithmic production frontiers," The Review of Economics and Statistics, vol. 55, pp. 28-45, 1973.

[25] A. Sakamoto and C. Kim, "Is rising earnings inequality associated with increased exploitation? Evidence for U.S. manufacturing industries, 1971-1996," Sociological Perspectives, vol. 53, no. 1, pp. 19-43, 2010.

[26] A. S. Goldberger, A Course in Econometrics, Harvard University, Cambridge, Mass, USA, 1991. 


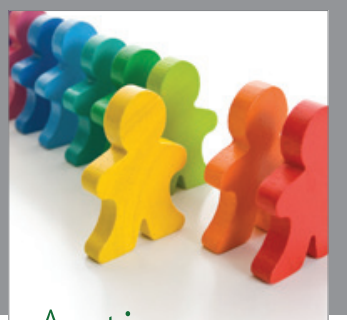

Autism

Research and Treatment
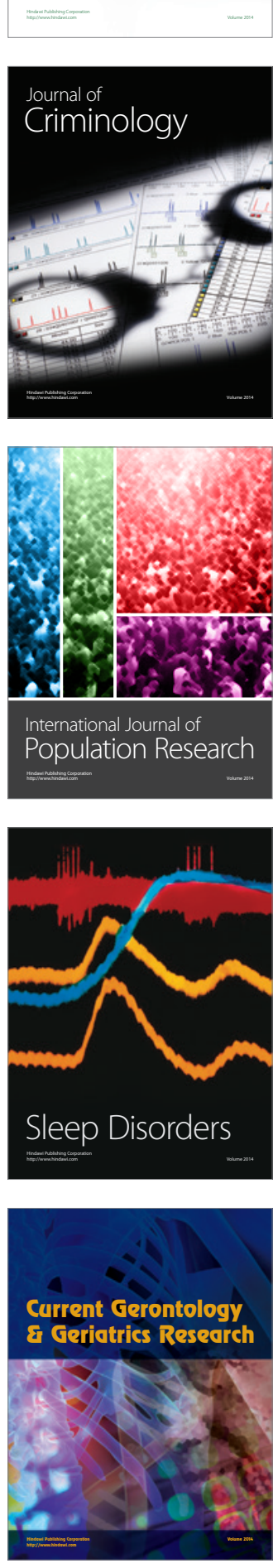
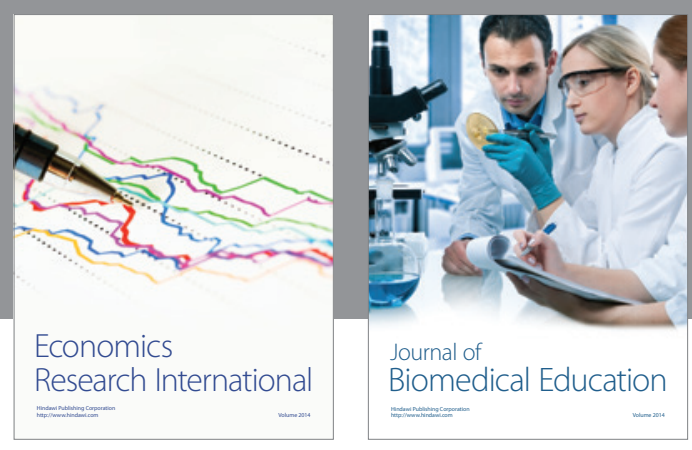

Journal of

Biomedical Education

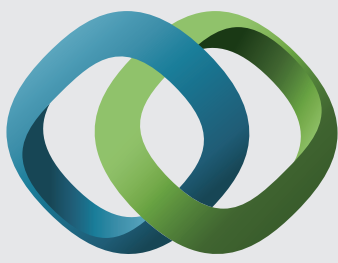

\section{Hindawi}

Submit your manuscripts at

http://www.hindawi.com
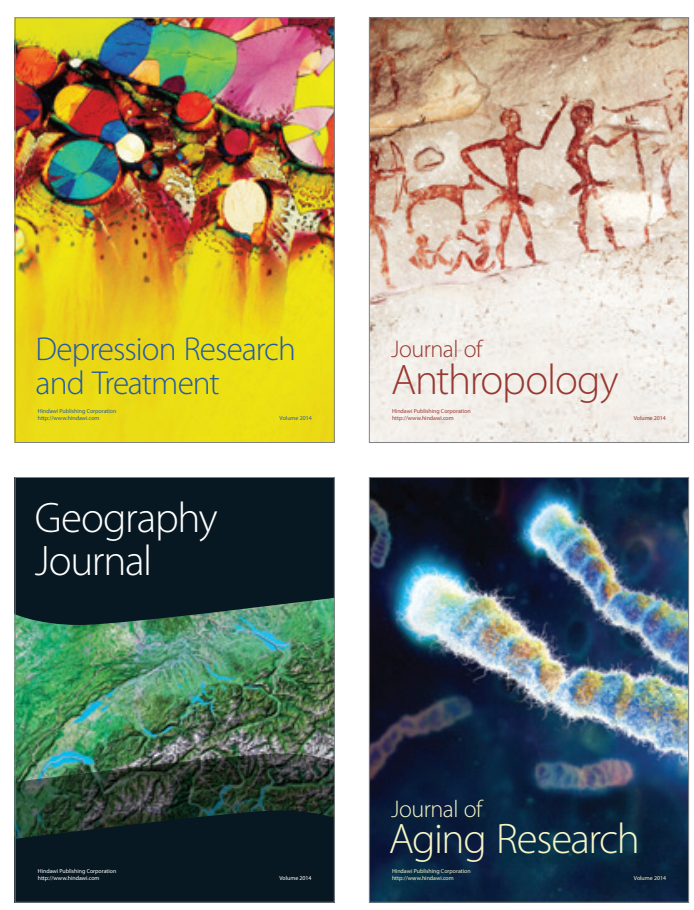

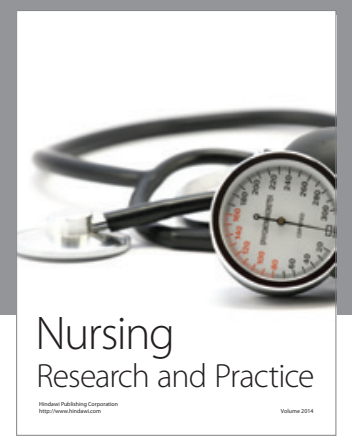

Nursing

Research and Practice

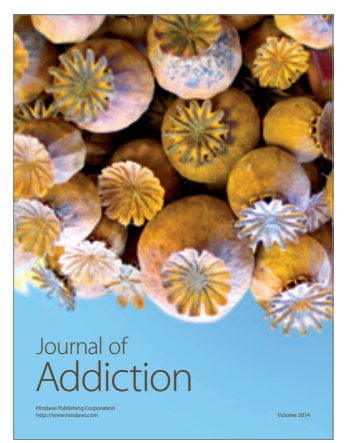

Child Development

Research

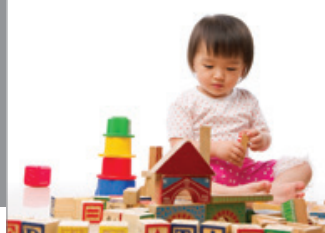

迥
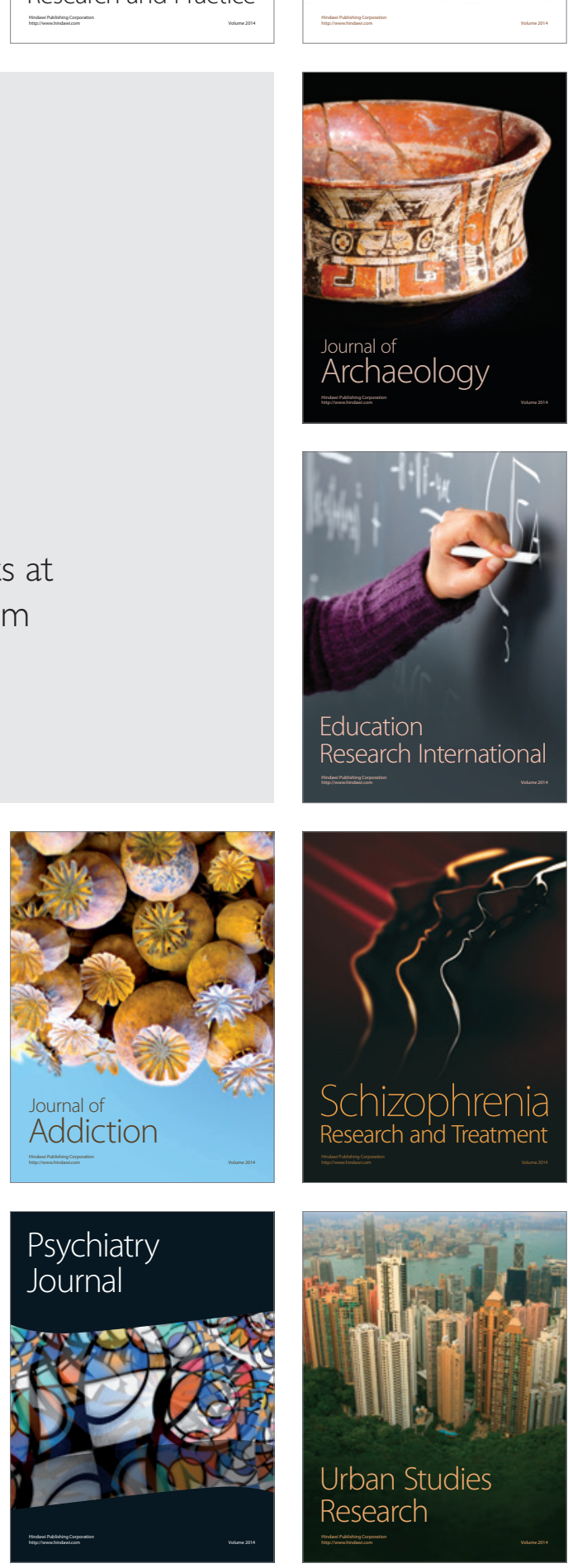